\title{
BMJ Global Health Effects of economic downturns on child mortality: a global economic analysis, 1981-2010
}

\author{
Mahiben Maruthappu, ${ }^{1}$ Robert A Watson, ${ }^{2}$ Johnathan Watkins, ${ }^{3}$ Thomas Zeltner, ${ }^{4}$ \\ Rosalind Raine, ${ }^{5}$ Rifat Atun ${ }^{6}$
}

To cite: Maruthappu M, Watson RA, Watkins J, et al. Effects of economic downturns on child mortality: a global economic analysis, 1981-2010. BMJ Global Health 2017;2:e000157. doi:10.1136/bmjgh-2016000157

- Additional material is published online only. To view please visit the journal online (http://dx.doi.org/10. 1136/bmjgh-2016-000157).

Received 13 August 2016 Revised 28 December 2016 Accepted 31 December 2016

CrossMark

For numbered affiliations see end of article.

\footnotetext{
Correspondence to

Dr Robert A Watson; robert.watson1@imperial. ac.uk
}

\section{ABSTRACT}

Objectives: To analyse how economic downturns affect child mortality both globally and among subgroups of countries of variable income levels.

Design: Retrospective observational study using economic data from the World Bank's Development Indicators and Global Development Finance (2013 edition). Child mortality data were sourced from the Institute for Health Metrics and Evaluation.

Setting: Global.

Participants: 204 countries between 1981 and 2010.

Main outcome measures: Child mortality, controlling for country-specific differences in political, healthcare, cultural, structural, educational and economic factors.

Results: 197 countries experienced at least 1 economic downturn between 1981 and 2010, with a mean of 7.97 downturns per country (range $0-21$; SD $0.45)$. At the global level, downturns were associated with significant $(p<0.0001)$ deteriorations in each child mortality measure, in comparison with non-downturn years: neonatal (coefficient: $1.11,95 \% \mathrm{Cl} 0.855$ to 1.37), postneonatal $(2.00,95 \% \mathrm{Cl} 1.61$ to 2.38$)$, child $(2.93,95 \% \mathrm{Cl} 2.26$ to 3.60$)$ and under 5 years of age (5.44, $95 \% \mathrm{Cl} 4.31$ to 6.58$)$ mortality rates. Stronger (larger falls in the growth rate of gross domestic product/capita) and longer (lasting 2 years rather than 1) downturns were associated with larger significant deteriorations $(p<0.001)$. During economic downturns, countries in the poorest quartile experienced $\sim 1 \frac{1}{2}$ times greater deterioration in neonatal mortality, compared with their own baseline; a 3-fold deterioration in postneonatal mortality; a 9-fold deterioration in child mortality and a 3-fold deterioration in under-5 mortality, than countries in the wealthiest quartile $(p<0.0005)$. For $1-5$ years after downturns ended, each mortality measure continued to display significant deteriorations $(\mathrm{p}<0.0001)$.

Conclusions: Economic downturns occur frequently and are associated with significant deteriorations in child mortality, with worse declines in lower income countries.

\section{INTRODUCTION}

The negative health effects of the recent global economic downturn are a major

\section{Key questions}

What is already known about this topic?

- Economic crises have been associated with adverse population health outcomes, although some studies have conversely failed to show negative effects on health outcomes during recessions.

- Economic downturns in developing countries have been associated with rises in maternal and infant mortality, with larger shocks associated with proportionally increased mortality.

- There is an absence of work comparing the effects of economic downturns on child health across all low-income, middle-income and highincome countries, important for prioritising and targeting policy interventions.

What are the new findings?

- This study uses global data to provide a direct comparison of the magnitude of economic downturns on child mortality between low-income, middle-income and high-income countries.

- Those children (under-5) in the poorest countries experienced a threefold deterioration in mortality during economic downturns when compared with those in the wealthiest countries.

- Children, who are the most vulnerable and innocent, experience adverse health outcomes during economic downturns, a phenomenon that is much more marked in poorer countries.

\section{Recommendations for policy}

- These findings reinforce the global dimension and critical importance of this issue

- Economic downturns occur arguably more commonly than pandemics or natural disasters and yet preventative and protective policies do not exist at the international level to ensure health system resilience during economic downturns.

- Notably, there are no internationally adopted strategies to mitigate risks to health outcomes during economic downturns.

- The strong association between economic downturns and adverse child mortality indicates the urgent need for a multilateral initiative to mitigate the risks of economic downturns on child health. 
concern worldwide. ${ }^{1}{ }^{2}$ Until now, several studies have explored theoretically and empirically the adverse health consequences of the economic crisis, ${ }^{3-5}$ with analyses of selected population health outcomes in single or small groups of countries. ${ }^{6-10}$ Indeed, the recent economic crisis has been estimated to be associated with over 260000 excess cancer deaths in the Organisation for Economic Co-operation and Development (OECD) alone. ${ }^{11}$ However, some studies have failed to show negative effects on health outcomes during recessions or conversely positive health benefits in times of economic growth. ${ }^{12-14}$ Until now, published studies have largely focused on the impact of economic changes on population health in high-income countries, ${ }^{6-10}{ }^{12-14}$ with a limited number analysing the health impact of economic crises on low-income and middle-income countries (LMICs). ${ }^{15-19}$ Since poorer nations, on the whole, tend to have weaker social welfare systems, secondary to politico-economic constraints, and have more fragile health systems, their populations may be more vulnerable to economic downturns.

The United Nations (UN) Standing Committee on Nutrition has demonstrated that recessions in developing nations are significantly associated with malnutrition among pregnant women and children. Congruently, economic shocks have been associated with rises in maternal and infant mortality in low-income countries. ${ }^{15-19}$ However, thus far the nature and magnitude of these adverse health effects have not been quantifiably compared with health economic trends in high-income countries.

To provide greater insight into the relationship between economic changes and population health outcomes, we analysed the impact of economic downturns on child mortality across 204 countries from 1981 to 2010. Child health is a global priority, having previously been the focus of the UN's Millennium Development Goal (MDG) $4,{ }^{20}$ now incorporated into the Sustainable Development Goal (SDG) 3. ${ }^{21}$ We analysed and compared these relationships for high-income and lowincome countries.

Our analysis is timely, given the 'severe funding shortfall' for maternal and child health reported by the Independent Expert Review Group (iERG). ${ }^{22}$

\section{METHODS}

\section{Data collection}

We used economic data from the World Bank's Development Indicators and Global Development Finance 2013 edition. $^{23}$ In this data set, data were extracted for 214 countries from 1981 to 2010. Data on gross domestic product (GDP)/capita (local currency units) were available for 204 of these countries (see online supplementary table A, appendix). We used child mortality data (neonatal, postneonatal, $1-5$ years (child) and under-5 mortality, defined in online supplementary table $\mathrm{O}$; see online supplementary appendix) reported by the Institute for Health Metrics and Evaluation, matched to the same time period, $1981-2010 .{ }^{24}$ Data were extracted for the years 1981-2010. Data were missing for some of the countries in some of the years, bringing the total number of country-years available to 4828 .

\section{Economic downturns and recessions}

A recession is typically defined as two consecutive quarters of negative economic growth. Data, however, were only available for GDP per capita on a yearly basis (World Bank data code NY.GDP.PCAP.KD.ZG). Hence, rather than recession, we used 'economic downturn' as our measure of negative economic growth. We defined an economic downturn as a year in which the GDP per capita was lower, by any amount, than that of the previous year. This measure captured more sustained downturns and excluded intra-annual statistical aberrations in GDP figures, which have been a point of controversy among economists. ${ }^{25}$ We measured GDP in constant local currency, and used the mid-year population figure of the country in question to calculate the per capita GDP figure. Robustness checks were introduced to assess the impact of the magnitude of downturns.

\section{Statistical analysis}

We used multivariate regression models to analyse the associations between economic downturns and population-level health outcomes. We measured the impact of downturns by adding a dummy variable to the multivariate regression model, which took 1 when a country was in a downturn and 0 when a country was not. We also assessed the impact of changes in the growth rate of GDP/capita (increases or decreases) on population health measures.

We included 203 dummy variables for each of the 204 countries, excluding an arbitrarily chosen reference country. Doing this meant that models evaluated mortality changes within individual countries while holding constant time-invariant differences between countries, including higher predispositions to child mortality as well as political, healthcare, cultural, structural, educational and economic differences. In effect, this modelling approach made the data more comparable and removed any potentially confounding between-country differences, thus isolating the association between economic downturns and child mortality. In addition, total population size and demographic structure (both the population over 65 and under 15 years of age) were included as further controls. While our approach held time-invariant differences between countries constant, as part of our robustness checks, we specifically introduced controls for factors likely to contribute to child health: additional political (armed personnel as a percentage of labour force), healthcare (diphtheria, polio and tetanus, and measles immunisation rates), cultural (percentage of the population living in urban areas), structural (water accessibility), educational (percentage of 
children with progression to secondary school) and economic factors. Controls were chosen based on data availability. This approach is based on methodology that has been used and validated in studies by our group and others. ${ }^{71}$ Since we included several control variables (in turn losing degrees of freedom and reducing sample size), our approach was conservative. ${ }^{26}$ Finally, given that the data were characterised by heteroscedasticity, we included robust SEs in the model. The regression model we used is shown by the equation:

$$
\Delta \mathrm{Hi}, \mathrm{t}-\Delta \mathrm{Hi}=\alpha+\beta \times(\Delta \mathrm{Ui}, \mathrm{t}-\Delta \mathrm{Ui})+\eta \times \mathrm{t}+\gamma \mathrm{i} \times \mathrm{t}+\varepsilon \mathrm{i}, \mathrm{t}
$$

Where $\mathrm{i}$ is the country and $\mathrm{t}$ the year; $\mathrm{H}$ is the health metric; $\mathrm{U}$ is the measure of GDP/capita change over a year; $\alpha$ represents the population structure of the country being analysed, $\eta$ is a dummy variable for each country included in the regression model, and $\gamma$ the countryspecific rate of acceleration in the mortality rate from the health condition being analysed; and $\varepsilon$ is the error term.

We explored the effect of stronger downturns on measures of child health outcomes by analysing withindownturn changes in the growth rate of GDP/capita. We also conducted regressions to analyse the effect of the length of the economic downturn-comparing the second and subsequent years of multi-year downturns to the first year of all downturns. A 1-5-year time-lag multivariate analysis was also conducted to quantify the effect of downturns on child health measures up to 5 years after the year in which the downturns took place, controlling for intralag downturns.

Countries were also stratified into quartiles based on GDP per capita. A country's rank and subsequent quartile was calculated based on its average GDP per capita (2000 US\$ standardised) from 1981 to 2010 (see online supplementary table A, appendix). Data were not available for 5 of the 204 countries (see online supplementary table A, appendix). The aforementioned multivariate regression analyses were conducted to measure the association between downturns and health outcomes within each quartile. We conducted several robustness checks detailed in the Results section.

All data and models were conducted using Stata SE V.12 (Stata Corporation).

\section{RESULTS}

Table 1 shows the results of regression models for 204 countries between 1981 and 2010, after controlling for population size, demographic structure and countryspecific differences in healthcare infrastructure and wealth, using a dummy variable for economic downturns and a fixed-effects approach.

Of the 204 countries analysed, 197 experienced at least one economic downturn between 1981 and 2010, with a mean of 7.97 downturns per country across the period (SD 0.45; range 0-21 downturns). At the global level, downturns were associated with significant $(\mathrm{p}<0.0001)$ deteriorations in each child mortality measure analysed, in comparison with non-downturn years: neonatal (coefficient: $1.11,95 \%$ CI 0.855 to 1.37 ), postneonatal $(2.00,95 \%$ CI 1.61 to 2.38$)$, child (2.93, 95\% CI 2.26 to 3.60 ) and under 5 years of age (5.44, 95\% CI 4.31 to 6.58 ) mortality rates. Table 2 examines all years where there was a change in GDP per capita (either an increase or a decrease) and thereby provides a broader analysis of the link between the economy and child mortality. The impact of a $1 \%$ change in GDP/ capita on the four child mortality measures used is displayed. Annual changes in GDP/capita were associated with significant changes in each child mortality measure ( $p<0.0001)$, congruent with results obtained when using an economic downturn dummy variable only.

Table 1 The effects of economic downturns on child health outcomes

\begin{tabular}{llllcc}
\hline Child health outcome analysed & Coefficient & Robust SE & p Value & 95\% Lower Cl & 95\% Higher Cl \\
\hline Neonatal mortality & 1.1145 & $(0.13250)$ & $0.0000^{\star \star *}$ & 0.8547 & 1.3742 \\
Postneonatal mortality & 1.9954 & $(0.19718)$ & $0.0000^{\star \star *}$ & 1.6088 & 2.3820 \\
$1-5$ (child) mortality & 2.9290 & $(0.34311)$ & $0.0000^{\star \star *}$ & 2.2564 & 3.6017 \\
Under-5 mortality & 5.4420 & $(0.57864)$ & $0.0000^{\star \star *}$ & 4.3076 & 6.5764 \\
\hline
\end{tabular}

${ }^{*} p<0.05,{ }^{* *} p<0.01,{ }^{* \star} p<0.001$. Total number of observations for each row: 4828 .

Table 2 The effects of GDP/capita changes on child health outcomes

\begin{tabular}{llllll}
\hline Child health outcome analysed & Coefficient & Robust SE & p Value & 95\% Lower Cl & 95\% Higher Cl \\
\hline Neonatal mortality & -0.0681 & $(0.01124)$ & $0.0000^{\star * *}$ & -0.0901 & -0.0461 \\
Postneonatal mortality & -0.1364 & $(0.01940)$ & $0.0000^{\star * *}$ & -0.1744 & -0.0984 \\
$1-5$ (child) mortality & -0.1641 & $(0.02725)$ & $0.0000^{\star * *}$ & -0.2176 & -0.1107 \\
Under-5 mortality & -0.3315 & $(0.05011)$ & $0.0000^{\star * *}$ & -0.4297 & -0.2332 \\
\hline
\end{tabular}

${ }^{\star} p<0.05,{ }^{* *} p<0.01,{ }^{* \star} p<0.001$. Total number of observations for each row: 4828. 
Using the same models, multiple regression analysis showed decreases in health spending from public sources, measured as a percentage of GDP, were associated with significant $(\mathrm{p}<0.005)$ increases in neonatal (coefficient: $0.40,95 \%$ CI 0.26 to 0.55 ), postneonatal $(0.57,95 \%$ CI 0.34 to 0.79$)$, children aged $1-5$ years $(1.40,95 \%$ CI 1.00 to 1.80$)$ and children under 5 years of age $(2.15,95 \%$ CI 1.47 to 2.84$)$ mortality rates. Decreases in health spending from public sources were also associated with significant declines $(p<0.001)$ in physician availability (number of physicians per 100000 ; coefficient: $-0.070,95 \%$ CI -0.1 to -0.39 ), percentage of births attended by skilled health staff $(-0.53,95 \%$ CI -1.13 to -0.045$)$ and total hospital beds per 1000 people $(-1.80,95 \%$ CI -0.27 to -0.09$)$.

One, 2, 3, 4 and 5 years after downturns ended, all four child mortality measures consistently displayed significant deteriorations, with the magnitude of coefficients decreasing overall as time from recessions elapsed ( $\mathrm{p}<0.0001$; see online supplementary table $\mathrm{B}$, appendix). Regression analyses focusing on intradownturn changes in metrics revealed that greater annual GDP declines were associated with significant deteriorations in neonatal, children aged $1-5$ years and under 5 years of age mortality $(\mathrm{p}<0.05$; see online supplementary table $\mathrm{C}$, appendix). Subsequent years of downturns (ie, years after the first year of multiyear downturns) were associated with significant deteriorations in all mortality measures compared with the first year of all downturns $(\mathrm{p}<0.005$; see online supplementary table $\mathrm{D}$, appendix).

Countries were stratified into quartiles based on mean GDP per capita from 1981 to 2010 (see online supplementary table E, appendix). Countries in each income quartile are listed in online supplementary table A, appendix. GDP/capita changes were associated with significant changes in the four child mortality measures $(p<0.005)$, both in the wealthiest and poorest quartiles. Compared with the wealthiest quartile, countries in the poorest quartile displayed larger, significant deteriorations in all four child mortality measures analysed. During downturns, countries in the poorest quartile experienced 1.64 times greater deteriorations in neonatal mortality; 3.33 times larger deteriorations in postneonatal mortality; 9.10 times greater deteriorations in $1-5$ years old child mortality and 3.48 larger deteriorations in under-5 mortality than did countries in the wealthiest quartile $(p<0.0005)$. Between 1981 and 2010, countries in the richest quartile experienced on average 7.31 downturns, and those in the poorest quartile experienced 10.07 downturns, demonstrating that the poorest countries, in addition to displaying the largest changes in the child mortality measures analysed during a downturn, experienced on average the greatest number of downturns.

\section{Robustness checks}

To assess the strength of these results, a series of robustness checks were conducted. First, two additional measures of GDP/capita were used: one that measured GDP in terms of purchasing power parity (PPP) in constant 2005 international dollars, and the other which measured GDP in terms of PPP in current international dollars. The results were unaffected; all mortality measures still displayed significant associations with recessions and changes in GDP/capita (see online supplementary tables F and G, appendix). Second, removing metric observations with year-to-year fluctuations exceeding $150 \%$ did not change results. Third, when controlling specifically for political, structural and cultural factors likely to contribute to child health (as defined in the Methods section), largely similar results were obtained (see online supplementary tables $\mathrm{H}$ and I, appendix). Despite attenuation of findings due to decreased sample sizes and therefore power, downturns continued to be associated with significantly worse child mortality. Controlling for educational factors did not affect our findings, with all metrics remaining significant. Further, controlling for specific healthcare factors did not change results; economic downturns continued to be significantly associated with worse child mortality. Fourth, we included inflation in the regression model. There was complete overlap between these results and those of the original regressions (see online supplementary tables $\mathrm{J}$ and $\mathrm{K}$, appendix). Fifth, to account for variations in surveillance strength and data recording between countries, and the possibility that data quality from poorer nations may be less robust, we restricted our analysis to 'level 1' and 'level 2' quality data sources as defined by the WHO, removing 106 countries from the analysis (see online supplementary table L, appendix). Downturns and changes in the growth rate of GDP/capita were associated with significant changes in each of the child mortality measures; displaying highly similar coefficients. Sixth, we used World Bank mortality data as an alternative source for our analyses. Economic downturns were associated with significant increases in child mortality measures (see online supplementary table $\mathrm{M}$; appendix); this remained the case when restricting analyses to level 1 and 2 data sources (see online supplementary table $\mathrm{N}$, appendix).

\section{DISCUSSION \\ Principal findings}

Our analysis has provided new insights into the adverse impact of economic downturns on child mortality globally, especially in low-income countries. Economic downturns were shown to be frequent, and associated with significant deteriorations in the four child mortality measures analysed. Deteriorations were found in rich and poor countries alike, worsening with downturn strength (larger relative GDP/capita declines) and duration (downturns lasting more than 1 year). For 1-5 years after downturns ended, each mortality measure continued to display significant deteriorations. Poorer countries (those in the lowest per capita GDP 
income quartile) experienced the largest changes in child mortality, in some cases up to nine times that of wealthier countries, and on average experienced the greatest number of downturns.

\section{Strengths and weaknesses of the present study}

The present study used global data, taken from highquality, objective and centralised databases, avoiding both selection and recall bias. The volume of data used allowed for high statistical powering, providing confidence in the results obtained. Our study demonstrates the adverse effects of economic downturns on child health at a macro level, allowing an analysis of global trends over a long time period. In addition, our work used three measures of economic downturns (GDP per capita in local currency units, PPP (2005 international dollars) and PPP (current international dollars)), employing both an economic downturn dummy and crude GDP per capita changes, in addition to adjusting for sociodemographic and intercountry variations, incorporating over 200 controls.

It is important, however, to note the limitations of this study. First, we performed an analysis of 204 countries to provide a global analysis. This limits the applicability of our findings at the national and subnational level. Second, our study focused on child mortality measures, limiting identification and analysis of causal factors linking economic downturns to health. Third, we defined economic downturns as annual declines in GDP/capita, excluding changes at the quarterly or semiannual level. This may have resulted in an overrepresentation of economic changes more commonly occurring in developing countries than those in developed countries. We were also unable to model the effect of downturns on different strata of society; given the effect of downturns on socioeconomic status (figure 1), we would expect changes in the growth rate of GDP per capita to have the largest impact on the poorest members of society. Fourth, we were unable to control for relative differences between countries in overall spending on healthcare. Fifth, we did not account for endogeneity, as we assume that economic changes have an effect on public health outcomes. However, the pathway could theoretically be the opposite: increases in mortality could cause economic downturns. We consider this to be unlikely, unless the mortality levels are very large; it seems implausible to suggest that changes in public health would have a significant effect on GDP per capita particularly in the short term, although we accept that such an effect is more likely in the developing world. ${ }^{27}$ Further, as a robustness check, we reran analyses adjusting for such factors; the association between downturns and child mortality remained (see online supplementary tables $\mathrm{H}$ and I, appendix). Sixth, our study is retrospective and observational; it is not a prospective study and so we are only able to comment on association. Evidently, an experiment could not be done to test our hypothesis-for example, by modifying the GDP per capita of a country while holding all other factors constant. Finally, we only investigated the shortterm impact of economic downturns; previous studies have demonstrated that the impact of such downturns can be both delayed and long-lasting. ${ }^{28}$

\section{Strengths and weaknesses compared with other studies}

In the context of the studies focusing on child health effects of economic recessions and economic crises, there is a small body of literature suggesting an association between economic shocks and increased child mortality. ${ }^{15-19}$ Unlike previous work, ${ }^{15}$ we were unable to
Figure 1 Potential causal pathways linking economic downturns to increases in child mortality.
Potential causal pathways linking economic downturns to increases in child mortality.

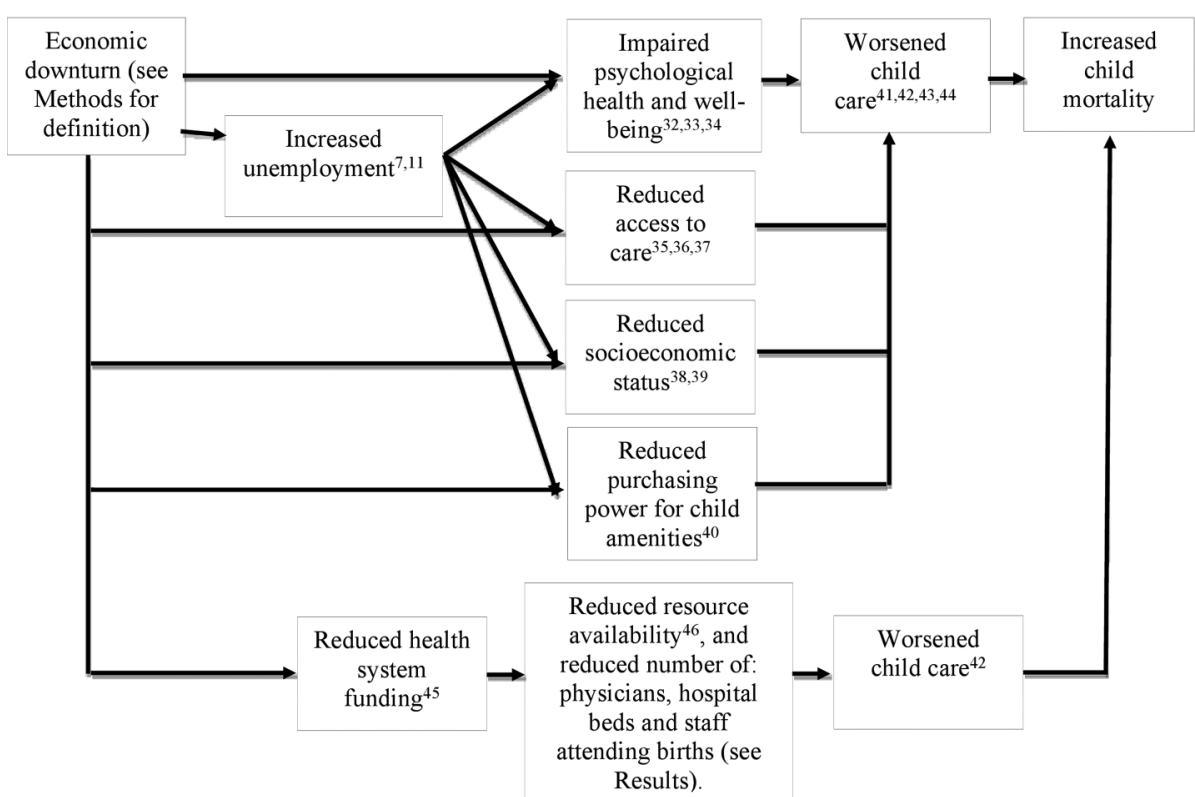


report differential results by child gender or maternal characteristics; or examine the effect of the magnitude of the economic shock on child mortality. However, much of the existing literature looks at only a subset of countries in the developing world, with limited comparisons across countries with different incomes. We have therefore provided, for the first time, a direct comparison of the effect of economic downturns on child mortality across low-income, middle-income and highincome countries. By stratifying countries into quartiles by GDP per capita, we were able to make comparisons across income brackets. Countries in the lowest income quartile displayed the largest deteriorations in the child health outcomes measured and also experienced the greatest number of recessions. Our work allows for these important direct comparisons, providing the international community with evidence of a relative disadvantage to children in poorer countries during economic downturns and allowing for more targeted and prioritised interventions.

Further, our current work, in part due to the inclusion of LMICs, counters some earlier studies from higher income countries suggesting that recessions may be associated with improved health outcomes, or the reciprocal argument that economic growth may be associated with worsened health outcomes ${ }^{12-14}$-and provides a caution in developing policy recommendations for LMICs by extrapolating findings of studies in high-income nations (such as those mentioned).

\section{Meaning of the study}

This work demonstrates the vulnerability of young children who are often the first, and most innocent, victims of major social disruption. The fact that the association is larger in lower income countries lends credence to the thought that it is those at the margins of poverty who are the primary sufferers and that those systems with limited health expenditures are less resilient to economic shocks.

The mechanisms by which economic downturns affect population health outcomes warrant further investigation. Figure 1 summarises potential causal mechanisms based on our analyses and current literature. ${ }^{29-44}$ Economic downturns are likely to adversely impact child mortality by negatively influencing the provision of care for children at the individual level, and reducing health spending at the system level. Notably, downturns have a number of consequences that negatively affect parents' ability to maintain good child health. During downturns, people are likely to be-or feel-poorer. ${ }^{45}{ }^{46}$ Parents may reduce food purchases, or purchase poorer quality food, ${ }^{47}$ leading to lower levels of child nutrition and hence higher mortality. ${ }^{49}$

Medical care may also worsen during economic downturns. Particularly in countries where health expenditures are predominantly out of pocket-that is, where essential services are not publicly financed-parents may reduce access to health services to save money. ${ }^{50} 51 \mathrm{In}$ addition, the quality of medical care on offer may decline, as downturns lead to lower hospital budgets. ${ }^{40}$ Both of these processes would contribute to lower child healthcare and hence to higher mortality. Our analyses also demonstrate that reduced healthcare spending, frequently experienced during economic downturns, ${ }^{40}$ is associated with significant decreases in physician availability, hospital bed availability and, in turn, rises in all measures of child mortality.

Our finding that 197 countries experienced economic downturns during 1981-2010, the period of analysis, on average eight times each, reinforces the global dimension and critical importance of this issue for public health. In particular, the risks posed to child health by frequent economic downturns warrant discussion. Although economic downturns occur arguably more commonly than pandemics or natural disasters, ${ }^{52} 53$ and affect a range of health outcomes; preventative and protective policies do not exist at the national or international level to ensure health system resilience during economic downturns. Notably, there are no internationally adopted strategies to mitigate risks to health outcomes during economic downturns, despite the concerns raised by the UN in 2009 .

\section{Unanswered questions and future research}

As described, detailed work to develop and implement an international initiative aimed at preserving child health during economic downturns is well overdue. The strong association between economic downturns and adverse child mortality indicates an urgent need for a multilateral initiative to mitigate the risks of economic downturns on child health. Further work, including analysis at the national and subnational levels and to further elucidate and unpick likely causal factors would assist policymakers in the funding and implementation of high value interventions. Additional research and policy interventions, particular in lowincome countries, could potentially address avoidable child mortality.

\section{Author affiliations}

${ }^{1}$ Academic Clinical Fellow \& Public Health Registrar, University College London, London, UK

${ }^{2}$ Department of Primary Healthcare and Public Health, Imperial College London, London, UK

${ }^{3}$ PILAR Research and Education, Cambridge, UK

${ }^{4}$ Global Health Centre, Graduate Institute of International and Development Studies, Geneva, Switzerland

${ }^{5}$ Head of Department of Applied Health Research, University College London, London, UK

${ }^{6}$ Harvard School of Public Health, Harvard University, Cambridge, Massachusetts, USA

\section{Handling editor Sanni Yaya.}

Acknowledgements The authors are grateful to the Department of Ethics and Social Determinants of Health of the WHO for reviewing this study. The authors are also grateful to Professor Amartya Sen (Harvard University), Dr Antoine Duclos (University of Lyon), Dr Anthony Hotson (University of Oxford), Fran Bennett (University of Oxford), Harry Moss, Dr David Stuckler 
(University of Oxford), Dr Aaron Reeves (University of Oxford) and Callum Williams (The Economist). RR is supported by the National Institute for Health Research (NIHR) Collaboration for Leadership in Applied Health Research and Care (CLAHRC) North Thames at Bart's Health NHS Trust.

Disclaimer The views expressed are those of the author(s) and not necessarily those of the NHS, the NIHR or the Department of Health.

Contributors MM, RA and TZ were involved in study concept and design; MM, RA, TZ, JW, RAW and RR were involved in data analysis and interpretation; MM, RA, TZ, JW, RAW and RR were involved in manuscript preparation and revision. All authors had full access to all of the data in the study and can take responsibility for the integrity of the data and the accuracy of the data analysis. The lead author (MM; the manuscript's guarantor) affirms that the manuscript is an honest, accurate and transparent account of the study being reported; and that any discrepancies from the study as planned (and, if relevant, registered) have been explained.

Competing interests None declared.

Provenance and peer review Not commissioned; externally peer reviewed.

Data sharing statement All data used are publicly available. Links are provided in the manuscript.

Open Access This is an Open Access article distributed in accordance with the Creative Commons Attribution Non Commercial (CC BY-NC 4.0) license, which permits others to distribute, remix, adapt, build upon this work noncommercially, and license their derivative works on different terms, provided the original work is properly cited and the use is non-commercial. See: http:// creativecommons.org/licenses/by-nc/4.0/

\section{REFERENCES}

1. Catalano R. Health, medical care, and economic Crisis. $N$ Engl $J$ Med 2009;360:749-51.

2. Horton R. The global financial crisis: an acute threat to health. Lancet 2009;373:355-6.

3. Williams C, Maruthappu M. Healthconomic crises, public health and neoliberal economic crises. Am J Public Health 2013;103:7-9.

4. Maruthappu M, Williams C. The biomarket. Glob Public Health 2013;8:106-19.

5. Maruthappu M, Williams C. Reversing the WHO crisis: transparent priority matching of global needs with donor objectives. BMJ 2012;345:e7815.

6. Brenner HM. Mortality and the national economy. Lancet 1979;314:568-73.

7. Stuckler D, Basu S, Suhrcke M, et al. The public health effect of economic crises and alternative policy responses in Europe: an empirical analysis. Lancet 2009;374:315-23.

8. Stuckler D, Basu S, Suhrcke M, et al. The health implications of financial crisis: a review of the evidence. Ulster Med J 2009;78:142-5.

9. Barr B, Taylor-Robinson D, Scott-Samuel A, et al. Suicides associated with the 2008-10 economic recession in England: time trend analysis. BMJ 2012;345:e5142.

10. Rihmer Z, Kapitany B, Gonda X, et al. Suicide, recession, and unemployment. Lancet 2013;381:722-3.

11. Maruthappu M, Watkins J, Noor AM, et al. Economic downturns universal health coverage, and cancer mortality in high-income and middle-income countries, 1990-2010: a longitudinal analysis. Lancet 2016;388:684-95

12. Ruhm CJ. Are recessions good for your health? $Q J$ Econ 2000;115:617-50.

13. Tapia Granados JA. Increasing mortality during the expansions of the US economy, 1900-1996. Int J Epidemiol 2005;34:1194-202.

14. Gerdtham UG, Ruhm CJ. Deaths rise in good economic times: evidence from the OECD. Econ Hum Biol 2006;4:298-316.

15. Baird S, Friedman J, Schady N. Aggregate income shocks and infant mortality in the developing world. Rev Econ Stat 2011;93:847-56.

16. Balhotra S. Fatal fluctuations? Cyclicality in infant mortality in India. IZA 2007; Discussion Paper No. 3086.

17. Cruces GG, Lopez-Calva LF. Economic crises, maternal and infant mortality, low birth weight and enrollment rates: evidence from Argentina's downturns. IZA 2011; Discussion Paper No. 6096.

18. Paxson C, Schady N. Child health and economic crisis in Peru. World Bank Econ Rev 2005;19:203-23.
19. Friedman J, Schady N. How many infants likely died in Africa as a result of the 2008-2009 global financial crisis? Health Econ 2013;22:611-22.

20. World Health Organization. Millenium Development Goals. http:// www.who.int/topics/millennium_development_goals/child_mortality/ en/ (accessed Jul 2016).

21. World Health Organization. Sustainable Development Goals. https://sustainabledevelopment.un.org/?menu=1300 (accessed Oct 2016).

22. Every Woman, Every Child: Strengthening Equity and Dignity through Health: the second report of the independent Expert Review Group (iERG) on Information and Accountability for Women's and Children's health. World Health Organization, 2013. http://apps.who. int/iris/bitstream/10665/85757/1/9789241505949_eng.pdf (accessed April 2017).

23. World Bank. World development indicators. http://data worldbank.org/data-catalog/world-development-indicators (accessed Jul 2016).

24. Institute for Health Metrics and Evaluation. Infant and child mortality estimates by country 1970-2010. http://ghdx.healthdata.org/record/ infant-and-child-mortality-estimates-country-1970-2010 (accessed Jul 2016)25. Leamer E. What's a recession, anyway? National Bureau of Economic Research, 2008.

25. Leamer E. What's a recession, anyway? National Bureau of Economic Research, Working Paper No. 14221, 2008. http://www. nber.org/papers/w14221 (accessed April 2017)

26. Jones AM. Chapter 6 Health econometrics. Handbook of Health Economics. Culyer AJ, Newhouse JP (eds). Elsevier BV 2000:265-344. http://dx.doi.org/10.1016/S1574-0064(00)80165-1

27. Kirigia JM, Sambo LG, Aldis W, et al. The burden of natural and technological disaster-related mortality on gross domestic product (GDP) in the WHO Africa Region. Afr J Health Sci 2004;9:169-80.

28. Stuckler D, Meissner C, Fishback P, et al. Banking crises and mortality during the great depression: evidence from US urban populations, 1929-1937. J Epidemiol Community Health 2011;66:410-19.

29. Morris JK, Cook DG, Shaper AG. Loss of employment and mortality. BMJ 1994;308:1135-9.

30. Hammarström A. Health consequences of youth unemployment, a review from a gender perspective. Soc Sci Med 1994;38: 699-709.

31. Paul KI, Moser K. Unemployment impairs mental health: Meta-analyses. J Vocational Behav 2009;74:264-82.

32. Quinn BC, Catalano RA, Felber E. The effect of community-leve unemployment on preventive oral health care utilization. Health Serv Res 2009;44:162-81.

33. Driscoll AK, Bernstein AB. Health and access to care among employed and unemployed adults: United States, 2009-2010. NCHS Data Brief 2012;83:1-8.

34. Claxton $\mathrm{G}$, DiJulio $\mathrm{B}$, Whitmore $\mathrm{H}$, et al. Job-based health insurance: costs climb at a moderate pace. Health Aff (Millwood) 2009;28: w1002-w12.

35. Naish J. Poverty and child health, 2nd edition by Nick Spencer Radcliffe Medical Press, Oxford, 2000, 352 pages, f19.95, ISBN 1 85775477 8. J Adv Nurs 2001;35(2):307-07.

36. Spencer NJ. Poverty and child health. 2nd edn. Abingdon, UK: Radcliffe Medical, 2000

37. Mackenbach J, Bakker M, eds. Reducing inequalities in health a European perspective. London: Routledge, 2002.

38. Nakahara S, Poudel KC, Lopchan M, et al. Availability of childcare support and nutritional status of children of non-working and working mothers in urban Nepal. Am J Hum Biol 2006;18:169-81.

39. Spencer N. Social, economic, and political determinants of child health. Pediatrics 2003;112:704-6.

40. Chung $\mathrm{H}$, Muntaner $\mathrm{C}$. Political and welfare state determinants of infant and child health indicators: An analysis of wealthy countries. Soc Sci Med 2006;63:829-42.

41. Pritchard C, Williams R. Poverty and child (0-14 years) mortality in the USA and other Western countries as an indicator of "how well a country meets the needs of its children" (UNICEF). Int $J$ Adolesc Med Health 2011;23:251-5.

42. Wolfe I, Thompson M, Gill P, et al. Health services for children in western Europe. Lancet 2013;381:1224-34.

43. Martin A, Lassman D, Whittle L, et al. Recession contributes to slowest annual rate of increase in health spending in five decades. Health Aff (Millwood) 2011;30:11-22.

44. American Hospital Association. The economic crisis: ongoing monitoring of impact on hospitals [internet]. Chicago, IL: AHA, 2009 Nov 11 http://www.aha.org/aha/trendwatch/2009/ 09nov-econimpsurvresults.pdf. 
45. Cardoso E. Inflation and poverty. National Bureau of Economic Research, Working Paper No. 4006, 1992. http://www.nber.org/ papers/w4006 (accessed April 2017)

46. Saunders P. Poverty, inequality and recession. J Appl Econ Policy 1992;11:1-22.

47. Bhattacharya J, Currie J, Haider S. Poverty, food insecurity, and nutritional outcomes in children and adults. J Health Econ 2004;23:839-62.

48. Institute for Fiscal Studies. Gluttony in England? Long-term change in diet. 2013. http://www.ifs.org.uk/bns/bn142.pdf (accessed Jul 2016).
49. Rodríguez-Artalejo F, Garcés C, Gorgojo L, et al. Dietary patterns among children aged 6-7 y in four Spanish cities with widely differing cardiovascular mortality. Eur J Clin Nutr 2002;56:141-8.

50. Shahrawat R, Rao KD. Insured yet vulnerable: out-of-pocket payments and India's poor. Health Policy Plan 2011;27:213-21.

51. Batavia Al, Beaulaurier RL. Financial vulnerability of people with disabilities: assessing poverty risks. J Soc Soc Welfare 2001;28:139.

52. Morens DM, Folkers GK, Fauci AS. What is a pandemic? J Infect Dis 2009;200:1018-21.

53. Uyeki TM. $2009 \mathrm{H} 1 \mathrm{~N} 1$ virus transmission and outbreaks. $N$ Engl J Med 2010;362:2221-3. 